Gilang Putra Ramadhan, Eko Harry Susanto, Sisca Aulia: Analisis YouTube TVRI Dalam

Meningkatkan Jumlah Penonton

\title{
Analisis YouTube TVRI Dalam Meningkatkan Jumlah Penonton
}

\author{
Gilang Putra Ramadhan, Eko Harry Susanto, Sisca Aulia \\ gilang.915150079@stu.untar.ac.id, ekos@fikom.untar.ac.id, siscaa@fikom.untar.ac.id \\ Fakultas Ilmu Komunikasi Universitas Tarumanagara
}

\begin{abstract}
This study discusses youtube TVRI analysis in increasing the number of viewers. The purpose of this research is to find out and get an idea of the emergence of YouTube which encourages people to use YouTube as a source of information and entertainment. This study uses a qualitative approach with descriptive analysis and uses case study research methods as a basis for collecting data. Data collection techniques used by the author are interviews with several speakers and made observations to the social media section of TVRI. The results of this study are YouTube TVRI seeks to increase the number of viewers by presenting superior shows such as Korean drama Oshin, badminton matches in the country and abroad. Which is the difference with other television stations YouTube is YouTube TVRI has content about Indonesian culture.
\end{abstract}

Keywords: TVRI, Social Media, YouTube

\begin{abstract}
Abstrak
Penelitian ini membahas mengenai analisis youtube TVRI dalam meningkatkan jumlah penonton. Tujuan dari penelitian ini adalah untuk mengetahui dan memperoleh gambaran tentang kemunculan YouTube yang mendorong masyarakat menggunakan YouTube sebagai sumber informasi dan hiburan. Penelitian ini menggunakan pendekatan kualitatif dengan analisis deksriptif dan menggunakan metode penelitian studi kasus sebagai landasan untuk mengumpulkan data. Teknik pengumpulan data yang digunakan oleh penulis adalah wawancara dengan beberapa narasumber dan melakukan observasi ke bagian media sosial TVRI. Hasil dari penelitian ini adalah YouTube TVRI berupaya meningkatkan jumlah penonton dengan menampilkan tayangan-tayangan unggulan seperti drama korea oshin, pertandingan bulu tangkis dalam negeri dan luar negeri. Yang menjadi pembeda dengan YouTube milik stasiun televisi lain adalah YouTube TVRI memiliki konten-konten tentang kebudayaan Indonesia.
\end{abstract}

Kata Kunci: TVRI, Media Sosial, YouTube

\section{Pendahuluan}

TVRI menjadi stasiun televisi yang pertama dan satu-satunya milik negara. Pemerintah RI Nomor 13 Tahun 2005 Menetapkan bahwa tugas TVRI adalah memberikan pelayanan informasi, pendidikan dan hiburan yang sehat, kontrol dan perekat sosial, serta melestarikan budaya bangsa untuk kepentingan seluruh lapisan masyarakat melalui penyelenggaraan penyiaran televisi yang menjangkau seluruh wilayah Negara Kesatuan Republik Indonesia (http://tvri.go.id/about).

Visi dan misi TVRI tidak akan terwujud jika jumlah penonton semakin berkurang. Jumlah penonton harus ditingkatkan agar visi dan misi TVRI dapat diwujudkan. Penelitian mengenai faktor-faktor yang memprediksi diterimanya teknologi informasi menerima banyak perhatian karena banyak perusahaan mengadopsi dan menggunakan teknologi informasi (Dalam Eko Harry dan Sisca Aulia, Electronic Word of Mouth Dalam Proses Keputusan Konsumen:2018). Kemunculan 
media sosial menjadi ancaman bagi media konvensional. Akibatnya, masyarakat lebih suka menggunakan media sosial daripada media konvensional. Maka dari itu TVRI berupaya memanfaatkan media sosial dengan cara membuat channel YouTube yang berisui tentang hiburan, edukasi, informasi, dan siaran digital.

Dalam penelitian ini akan mencari tahu dan memperoleh gambaran tentang kemunculan YouTube yang mendorong masyarakat menggunakan YouTube sebagai sumber informasi dan hiburan. Serta mendefinisikan bagaimana upaya TVRI dalam memanfaatkan media sosial YouTube. Dengan penelitian ini diharapkan memberikan pengetahuan lebih bahwa ada banyak sekali media komunikasi yang dapat digunakan untuk mempermudah proses komunikasi.

\section{Metode Penelitian}

Pendekatan yang digunakan dalam penelitian ini adalah pendekatan kualitiatif dengan analisis deskriptif. Emzir menyatakan bahwa yang dikumpulkan lebih mengambil bentuk kata-kata atau gambar daripada angka-angka. Hasil penelitian tertulis berisi kutipan-kutipan dari data untuk mengilustrasikan dan menyediakan bukti presentasi (Emzir, 2016). Pendekatan kualitatif diguakan untuk mendapatkan data yang mendalam kemudian data yang terkumpul dianalisi untuk mendapatkan hasil analisa berupa penggambaran.

Dalam penelitian ini, metode penelitian yang digunakan adalah metode penelitian studi kasus. Menurut Crreswell (dalam Muh. Fitrah:2017) untuk memaksimalkan hasil penelitian, hendaknya peneliti menyelidiki secara cermat suatu program, peristiwa, aktivitas, proses atau sekelompok individu dengan mengggunakan prosedur pengumpulan data berdasarkan waktu yang telah di tentukan.

Metode pengumpulan data yang biasa digunakan adalah wawancara, untuk melengkapi data sebelumnya yang sudah ada. Data tambahan tersebut diperoleh dari perpustakaan, arsip, buku yang berhubungan dengan penelitian ini, dan jurnal-jurnal yang dipublikasikan secara umum. Subjek dari penelitian ini adalah perusahaan TVRI dan yang menjadi objek penelitian ini adalah YouTube TVRI.

Model analisi data penelitian kualitatif berdasarkan pendapat Miles dan Huberman (dalam Susanto, 2018 : 69) dilakukan melalui proses sebagai berikut: (1) Reduksi data sebagai proses pemilihan, pemusatan perhatian pada penyederhanaan, pengabstrakan dan transformasi data kasar yang muncul dari catatan-catatan tertulis dari lapangan. (2) Penyajian data sebagai sekumpulan informasi tersusun yang memberi kemungkinan adanya penarikan kesimpulan dan pengambilan tindakan. (3) Menarik kesimpulan/verifikasi merupakan kegiatan analisis yang ketiga, dari permulaan pengumpulan data seorang penganalisis kualitatif mulai mencari arti bendabenda, mencatat keteraturan, pola-pola, penjelasan, konfigurasi alur sebab akibat dan proposisi.

\section{Hasil Temuan dan Diskusi}

Era digital saat ini mempermudah manusia untuk mendapatkan informasi dimana saja dan kapan saja. Media konvensional sudah mulai ditinggalkan dan kurangnya peminat. Masyarakat sudah beralih ke media baru yang berbasis dengan internet, tentu saja ini sangat berbeda dengan media konvensional. YouTube merupakan turunan dari media baru yang berbentuk media sosial. Seiring dengan meningkatnya jumlah pengguna internet, pengguna YouTube juga meningkat pesat. 
Memiliki jumlah pengguna yang banyak membuat YouTube menjadi media yang potensial untuk mulai di manfaatkan. TVRI memilih YouTube sebagai salah satu media yang dapat menjangkau penonton secara lebih luas.

Media sosial memiliki kemampuan untuk memberikan informasi secara cepat dan menyeluruh. Dimana didalamnya juga terdapat interaksi yang berlangsung antara akun pengguna dan penonton berupa like dan komentar yang berisi saran dan masukan. Penonton juga bisa saling berinteraksi dengan penoton lainnya. Penonton bisa langsung memberikan umpan balik berupa like dan komentar secara langsung. Berbeda dengan televisi yang bersifat satu arah.

TVRI mulai menggunakan media sosial pada tahun 2012 dan baru mulai menggunakan YouTube sendiri pada tahun 2016 yang lalu. Namun pada saat ini TVRI sendiri belum memiliki divisi untuk media sosial itu sendiri. Saat ini hanya satu orang saja yang menangani semua media sosial yang dimiliki oleh TVRI, mulai dari Instagram, Facebook, Twitter dan juga YouTube. Tujuan dari dibuatnya channel YouTube TVRI ini adalah untuk mengikuti perkembangan teknologi yang sudah ada di tahap digital dan menghadapi persaingan dengan stasiun televisi lain. Karena stasiun televisi lain juga sudah memiliki channel YouTube masing-masing.

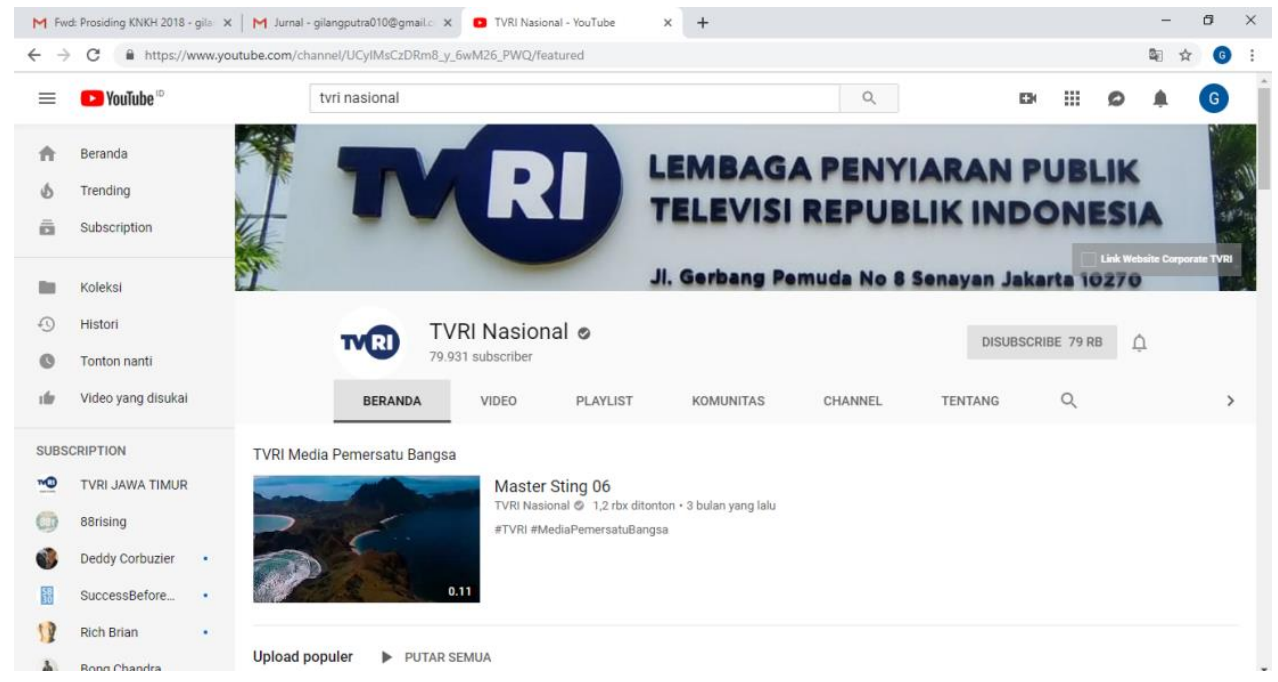

Gambar 1. Tampilan Depan YouTube TVRI

Sumber: https://www.youtube.com/watch?v=TA7089EnS9g\&t=28s

Pertama kali YouTube TVRI menampilkan live streaming yang terhubung langsung ke siaran utama di televisi. Namun tayangan live streaming tersebut tidak dapat tayang selama 24 jam. Tayangan yang tampil di live streaming TVRI adalah tayanga-tayangan yang diproduksi oleh produser-produser yang bekerja di TVRI itu sendiri. Tidak semua tayangan dapat tayang di live streaming karena ada beberapa tayangan yang hak ciptanya tidak dimiliki oleh TVRI. 


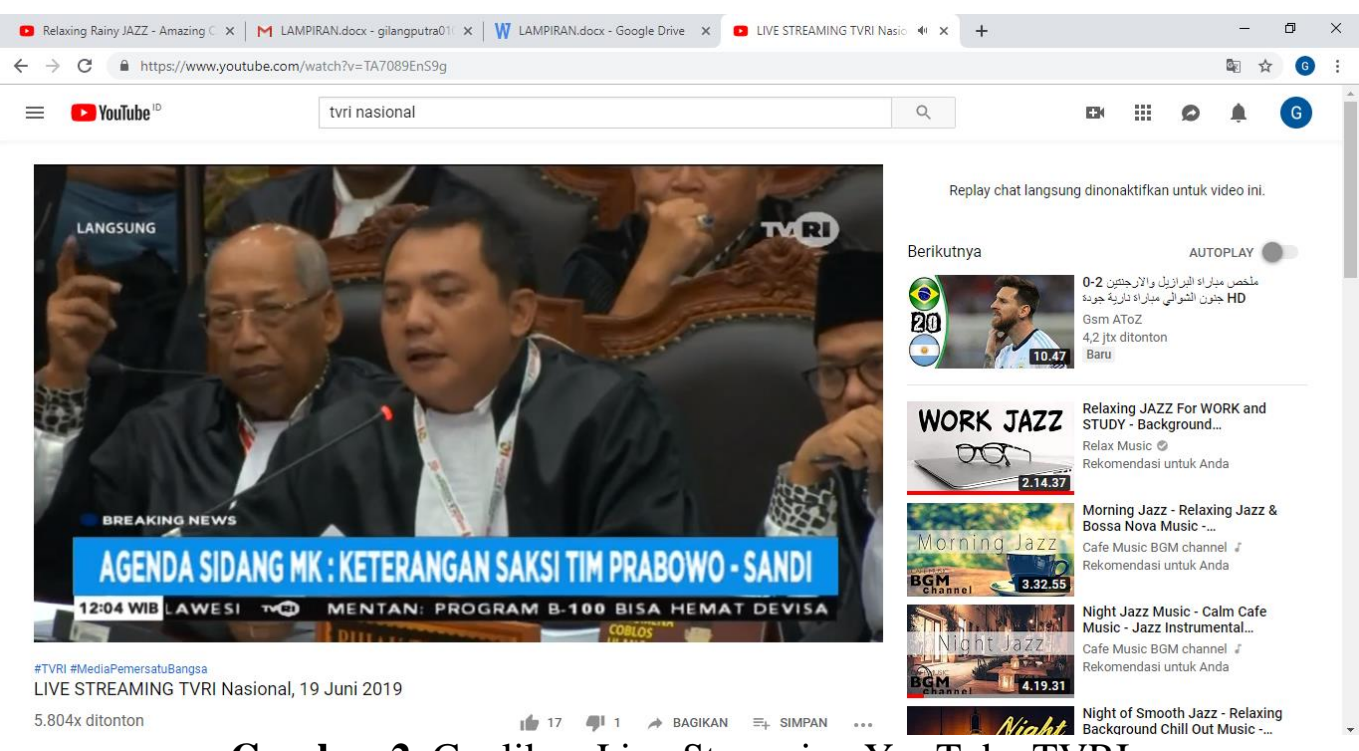

Gambar 2. Cuplikan Live Streaming YouTube TVRI

Sumber: https://www.youtube.com/watch?v=TA7089EnS9g\&t=28s

Tayangan yang dibeli oleh TVRI dari luar negeri dan hak cipta yang diberikan adalah hak cipta untuk tayangan on air. Jika hal dilanggar akan ada teguran berupa block world wide yang akan diberikan oleh pihak YouTube itu sendiri. Team media sosial TVRI juga harus berhati-hati dengan adanya copyright, terkadang, backsound yang digunakan untuk beberapa video terkena pelanggaran hak cipta. Kemudian terpaksa untuk di batalkan untuk di unggah ke channel YouTube TVRI. Karena di YouTube sendiri memiliki aturan dan regulasi tersendiri setiap video yang di upload. Contoh dari tayangan yang tidak dapat tayang di live streaming TVRI adalah tayangan drama Korea Oshin. Tayangan tersebut tetap tayang di YouTube TVRI dalam beberapa episode.

Selain live streaming, channel YouTube TVRI juga menampilkan beberapa program-program dan tayangan unggulan milik TVRI. Bagian media sosial TVRI juga bekerja sama dengan beberapa produser yang ada di TVRI, maksud dari tujuan tersebut adalah, agar tayangan yang di sutradarai oleh produser-produser TVRI bisa tayang juga di channel YouTube TVRI. Produser tersebut akan memberikan hasil rekaman tayangan ke admin media sosial untuk di unggah. Contoh dari tayangan unggulan yang ada di YouTube TVRI adalah tayangan pertandingan bulu tangkis luar negeri dan dalam negeri.

Selama ini tayangan yang ada di TVRI dianggap sudah tertinggal dan tidak mengikuti trend-trend yang sudah ada. Padahal saat ini TVRI sudah memiliki tayangatayangan yang sudah mengikuti perkembangan trend-trend yang ada pada saat ini. Film dari luar negeri juga sudah bisa tayang di siaran televisi 
Gilang Putra Ramadhan, Eko Harry Susanto, Sisca Aulia: Analisis YouTube TVRI Dalam Meningkatkan Jumlah Penonton

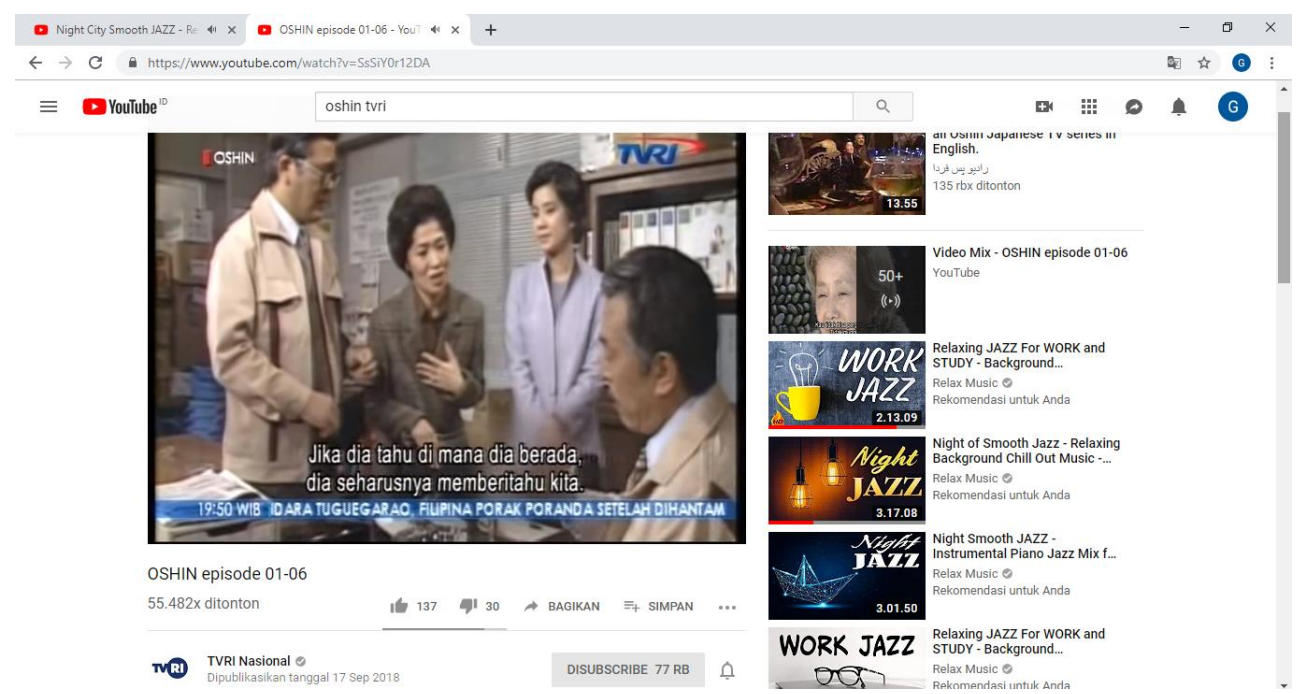

Gambar 3. Cuplikan Tayangan Drama Korea Oshin di YouTube TVRI

Sumber: https://www.youtube.com/watch?v=SsSiY0r12DA\&t=21s

Untuk menghadapi persaingan dengan stasiun televisi lainnya, TVRI juga menyiapkan konten yang berbeda dengan channel YouTube milik stasiun televisi lain. TVRI memiliki konten yang tidak dimiliki oleh stasiun televisi lain. Itu yang menjadi pembeda antara channel YouTube milik TVRI dengan channel YouTube milik stasiun televisi lain dan juga yang menjadi salah satu kelebihan dari channel YouTube milik TVRI.

Konten-konten seperti pesona Indonesia dan kebudayaan-kebudayaan Indonesia yang lebih banyak ditampilkan di channel YouTube TVRI. Mengacu pada tugas TVRI untuk melestarikan budaya bangsa kepada seluruh lapisan masyarakat. TVRI memiliki stasiun penyiaran di tiap-tiap provinsi yang ada di Indonesia. Tentu saja di setiap provinsi yang ada di Indonesia memiliki kebudayaan tersendiri. Kebudayaan tersebut terdiri dari adat istiadat, tari tradisional, keanekaragaman yang ada ditiap-tiap provinsi dan juga sejarah yang ada di provinsi tersebut.

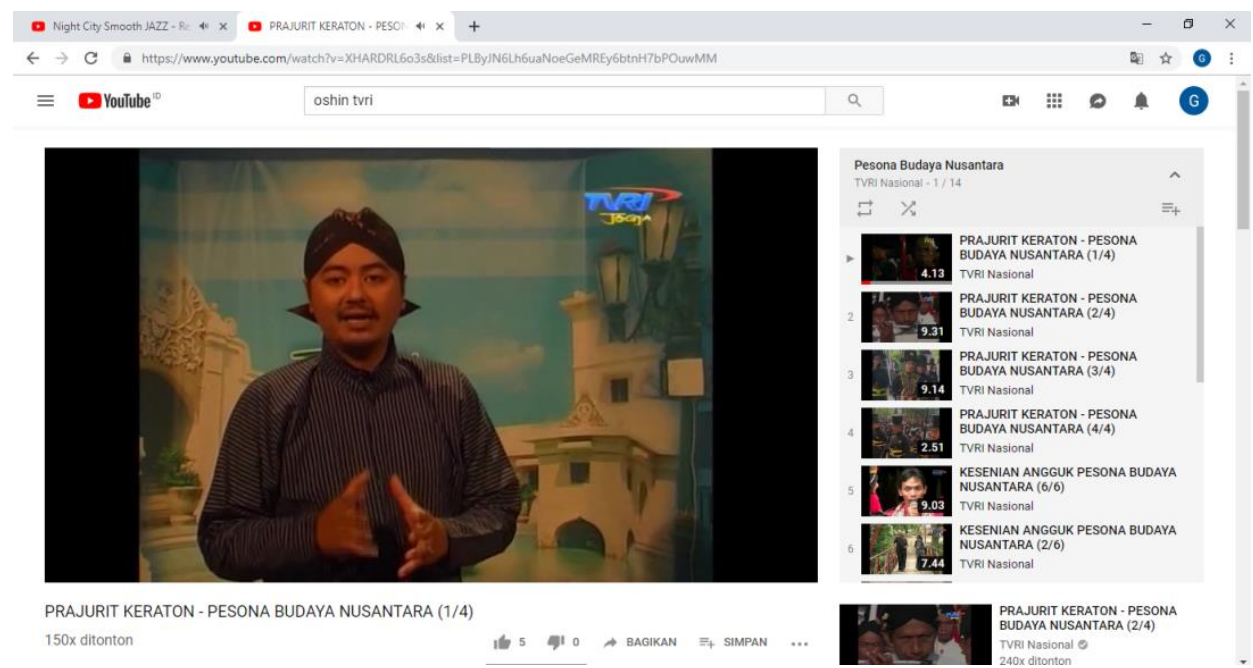

Gambar 4. Playlist Pesona Budaya Nusantara di YouTube TVRI

Sumber: https://www.youtube.com/watch?v=XHARDRL603s\&t=22s 
Tiap stasiun penyiaran yang ada di seluruh provinsi di Indonesia juga memiliki channel YouTube masing-masing. Seperti halnya TVRI Jogja memiliki playlist pesona budaya nusantara. Dimana dalam playlist tersebut berisikan vido-video tentang kebudayaan Indonesia. Bukan hanya dari kebudayaan Jawa saja yang dibahas, tapi dari kebudayaan yang ada di seluruh provinsi di Indonesia.

Monetized adalah salah satu fitur yang ada di YouTube agar video yang di unggah oleh pengguna dapat dipasangkan iklan. Pemilik video akan mendapatkan dollar sebagai bayaran, karena video yang di unggah berhasil dipasangkan iklan oleh YouTube. Saat ini video yang di upload ke channel YouTube milik TVRI sudah memenuhi persyaratan untuk monetized. Video yang di unggah saat ini oleh TVRI sudah pasti akan terpasang fitur monetized. Fitur tersebut akan memasang iklan secara otomatis ke video yang di unggah. Semakin banyak video itu dilihat oleh penonton. Maka akan lebih banyak pula pendapatan yang di dapat oleh TVRI.

Untuk meningkatkan jumlah penonton di setiap video yang ada, YouTube TVRI memiliki strategi untuk meningkatkan jumlah penonton di setiap video. Sehingga pendapatan dari monetized bisa bertambah. Strategi tersebut dengan menggunakan boosting, strategi tersebut akan membuat video yang di unggah menjadi tersebar lebih luas. Sehingga, jumlah view dan subscriber akan bertambah banyak dengan sendirinya.

YouTube TVRI mengalami peningkatan yang signifikan dari pertama pembuatannya. Peningkatan tersebut berasal dari jumlah subscriber dan jumlah view yang meningkat tiap bulannya. Peningkatan yang drastis tersebut karena YouTube TVRI bekerjasama dengan vendor Web TV Asia. Vendor tersebut bertugas untuk mengurus segala copyright mulai dari tayangan, musik serta backsound yang ada dalam video YouTube TVRI.

Peningkatan yang drastis terjadi pada awal tahun 2019. Statistik pertumbuhan menunjukan kenaikan yang drastis pada jumlah subscriber dan juga view. Pendapatan dari Monetized di tiap video juga bertambah lebih besar. Dengan adanya strategi boosting tersebut dan bekerja sama dengan Vendor Web Tv Asia, penonton YouTube TVRI akan terus meningkat dengan pesat dan juga subscriber yang terus bertambah.

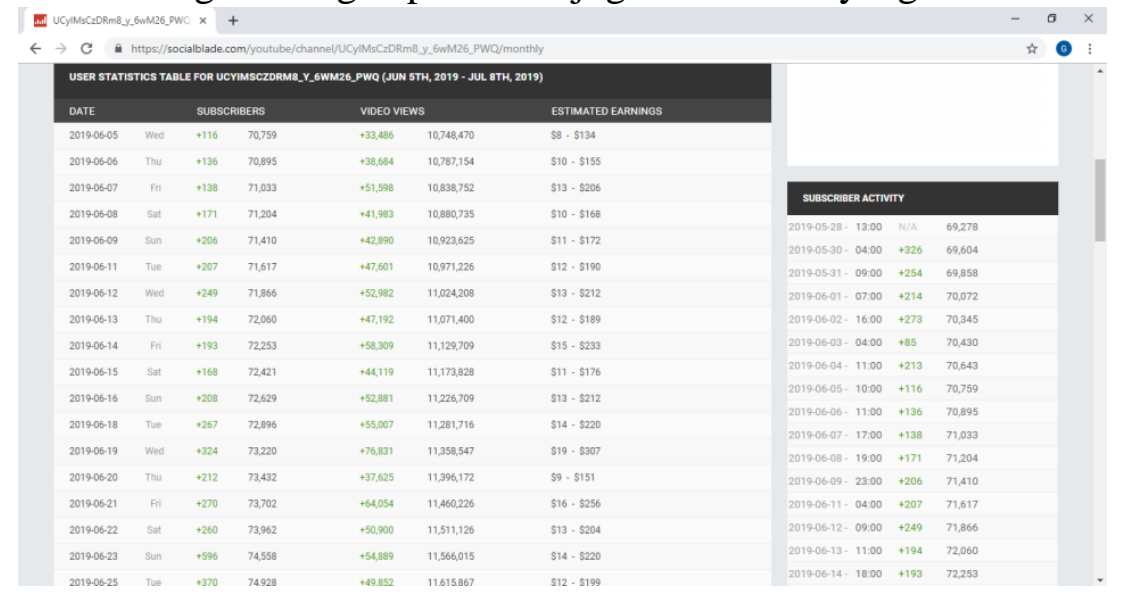

Gambar 5. Peningkatan Jumlah View dan Subscriber YouTube TVRI Sumber:https://socialblade.com/youtube/channel/UCyIMsCzDRm8_y_6 wM26_PWQ/monthl 
Gilang Putra Ramadhan, Eko Harry Susanto, Sisca Aulia: Analisis YouTube TVRI Dalam Meningkatkan Jumlah Penonton

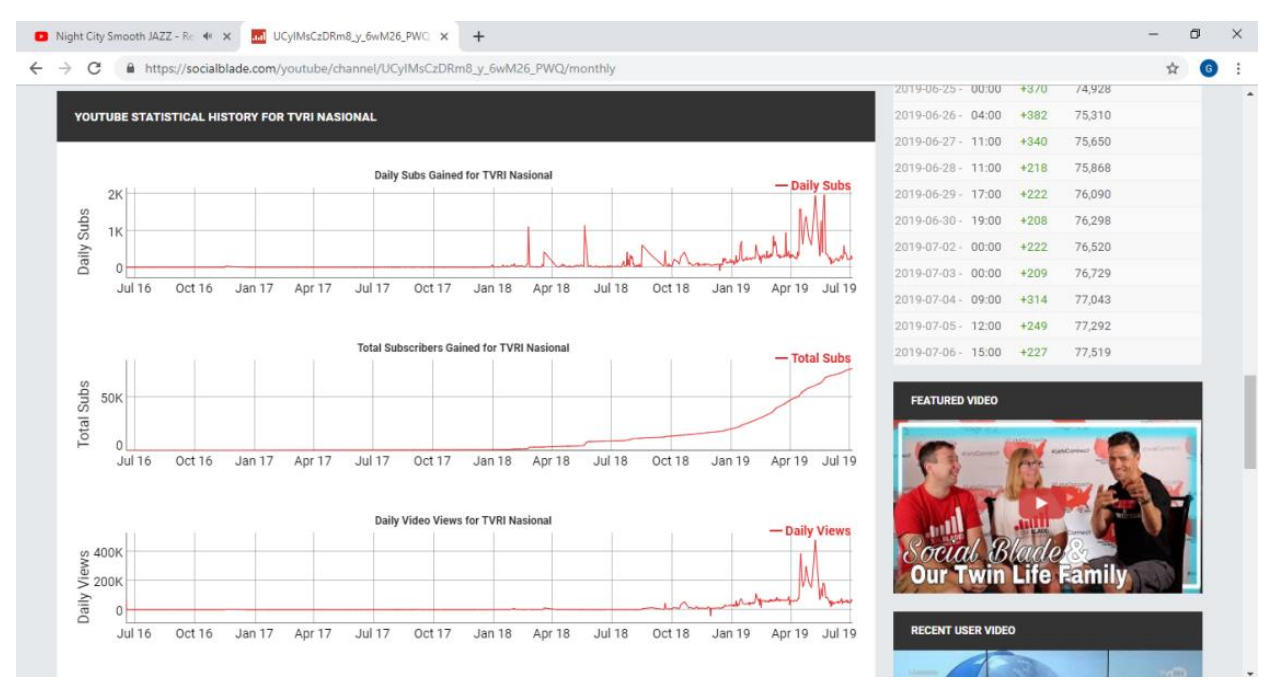

Gambar 6. Statistik Jumlah View dan Subscriber YouTube TVRI

Sumber:https://socialblade.com/youtube/channel/UCyIMsCzDRm8_y_6wM26 _PWQ/monthly

\section{Simpulan}

Perkembagan teknologi informasi dan komunikasi ke era digital membuat masyarakat lebih suka menggunakan media baru daripada media konvensional. Melihat fenomena tersebut, TVRI turut mengikuti perkembangan yang terjadi. Dengan membuat beberapa akun media sosial seperti Twitter,Facebook,Instagram dan YouTube. Melihat dari segi konten, YouTube TVRI memiliki konten yang bagus dan juga memiliki konten-konten kebudayaan Indonesia yang tidak dimiliki oleh akun YouTube milik stasiun televisi lain. Sehingga strategi ini bisa dijadikan untuk menghadapi persaingan dan menjadi pembeda dengan akun YouTube milik stasiun televisi lain. Selama ini TVRI di anggap sebagai media yang old style, maksudnya adalah tayangan-tayangan yang ada sudah tertinggal dan tidak mengikuti trend-trend yang ada pada saat ini. Padahal kenyataannya, tayangan-tayangan yang ada pada TVRI saat ini sudah mengikuti trend-trend yang ada pada saat ini.

Dilihat dari grafik perkembangan YouTube TVRI bahwa grafik tersebut menunjukan kenaikan yang signifikan terhadap jumlah view dan subscriber. Artinya makin banyak orang yang mulai tertarik dengan YouTube TVRI dan jumlah penonton juga meningkat. Jika jumlah penonton dan subscriber bertambah, maka pendapatan dari fitur monetized juga akan bertambah, Terlihat bahwa pendapatan TVRI juga meningkat tiap bulannya. Ada baiknya jika TVRI terus mempertahankan strategi tersebut agar tetap bisa bersaing dengan stasiun televisi swasta dan juga mendapatkan peningkatan jumlah penonton. TVRI juga harus bisa melakukan terobosa-terobosan baru di industri televisi agar bisa selangkah lebih maju.

\section{Ucapan Terima Kasih}

Peneliti ingin berterima kasih kepada seluruh narasumber yang telah berkontribusi dalam penulisan penelitian ini, terutama kepada Bapak Safaruddin sebagai team dari media sosial TVRI. Beliau telah bersedia meluangkan waktu menjadi narasumber dan menejelaskan upaya apa saja yang dilakukan oleh YouTube 
TVRI dalam meningkatkan jumlah penonton. Kedua, kepada Ibu Marta Warta Silaban sebagai dosen dari kampus London School of Public Relations yang juga meluangkan waktu untuk menjadi narasumber dalam penelitian ini. Beliau sebagai pengamat media telah menjelaskan kepada penulis bagaimana YouTube bisa menjadi pilihan utama dalam mencari informasi dan hiburan. Tentu saja masukan dari kedua narasumber penulis sangat bermanfaat dalam pengembangan penelitian ini. Peneliti juga ingin berterima kasih kepada Dr. Eko Harry Susanto, M.Si selaku pembimbing dan juga Ibu Sisca Aulia, S.I.Kom., M.Si selaku Co. pembimbing yang juga telah membantu penulis dalam menyelesaikan penelitian ini.

\section{Daftar Pustaka}

Emzir. (2016). Metodologi Penelitian Kualitatif: Analisis Data. Jakarta: PT RajaGrafindo Persada

http://tvri.go.id/about (diakses pada 17 Juli 2019)

Fitrah, Muh dan Lutfiyah. (2017). Metodologi Penelitian: Penelitian Kualitatif, Tindakan Kelas \& Studi Kasus. Sukabumi: CV Jejak.

Susanto, Eko Harry (2018). Komunikasi Manusia. Jakarta: Mitra Wacana Media

Susanto, Eko Harry dan Sisca Aulia. (2018). Electronic Word of Mouth Dalam

Proses Keptusan Konsumen (Studi Di Go-Jek). Prosiding KNKH

https://www.youtube.com/watch?v=TA7089EnS9g\&t=28s

(diakses pada 17 Juli 2019)

https://www.youtube.com/watch?v=SsSiY0r12DA\&t=21s

(diakses pada 17 Juli 2019

https://www.youtube.com/watch?v=XHARDRL6o3s\&t=22s

(di akses pada 17 Juli 2019)

https://socialblade.com/youtube/channel/UCyIMsCzDRm8_y_6wM26_PWQ/monthl (di akses pada 17 Juli 2019) 